Research Article

\title{
Estimation of Super High-Rise Pumping Pressure for High-Performance Concrete Based on Computational Fluid Dynamics Modeling and Situation Measurement
}

\author{
Weijiu Cui ${ }^{1}{ }^{1,2}$ Chuankai Zhao, ${ }^{1}$ and Sheng Wang ${ }^{3}$ \\ ${ }^{1}$ School of Civil Engineering, Qingdao University of Technology, Qingdao 266033, China \\ ${ }^{2}$ Innovation Institute for Sustainable Maritime Architecture Research and Technology, Qingdao University of Technology, \\ Qingdao 266033, China \\ ${ }^{3}$ Qingjian Group Co., Ltd., Qingdao 266011, China
}

Correspondence should be addressed to Weijiu Cui; cuiweijiu@163.com

Received 9 August 2021; Accepted 8 October 2021; Published 30 October 2021

Academic Editor: Guoming Liu

Copyright (c) 2021 Weijiu Cui et al. This is an open access article distributed under the Creative Commons Attribution License, which permits unrestricted use, distribution, and reproduction in any medium, provided the original work is properly cited.

\begin{abstract}
Traditional methods fail to predict the pumping pressure loss of high-performance concrete properly in super high-rise pumping situations due to complex changes of concrete properties. Therefore, it is imperative to propose a relative accurate method for pumping pressure estimation in super high-rise buildings. This paper builds the simplified pressure calculation method "pressure induced by the gravity plus pressure along the pipe line." The later one is gained by establishing topology optimized model based on computational fluid dynamics and considering the lubrication layer formation. The effect of rheological properties and flow rate is analyzed based on this model in detail. Furthermore, the developed calculation method is verified by the measured pumping pressure during the super high-rise building construction of the Shanghai Tower (the tallest building in China recently). The relative differences between the calculation results and the measured data in situ are less than $6 \%$, indicating the applicability of this method for predicting the pressure loss of the super high-rise pumping.
\end{abstract}

\section{Introduction}

Concrete pumping has been adopted in formwork casting for decades. It is widely used for concrete conveying during skyscraper construction because it is time-saving and environment-protecting. However, how to avoid pipeline leakage is still a bottleneck in the long-distance pumping process, such as super high-rise buildings, super long bridges, and long-distance tunnels, in which the pumping pressure plays a crucial role. This is mainly because both mixture design of fresh concrete and equipment selection depend on the prediction of pumping pressure, especially for super high-rise pumping.

Therefore, it is very important to predict the pumping pressure of concrete accurately and simply. ACI 304.2R-96 gives a chart used for calculation of the pressure loss [1]. In addition, technical specification for construction of concrete pumping provides an empirical formula for pressure per meter [2]. These specifications play a crucial guiding role in the traditional concrete pumping construction, but they are not suitable for the pressure prediction of high-performance concrete [3]. This is mainly due to the reason that the workability of high-performance concrete may be significantly affected by the addition of various superplasticizers or supplementary cementitious materials [4]. Therefore, as the rheological mechanism of concrete can not be fully considered, it is necessary to carry out research from the rheological point of view to modify the concrete pumping pressure calculated by the traditional estimation method. Fresh concrete is a viscoelastic-plastic body, and its flow is induced by shear actions [5]. The rheological parameters, especially the plastic viscosity and yield stress, are the key factors during the flow process [6-9]. Different rheological models, including Bingham model, Herschel and Bulkley 
model, and Casson model, have been proposed to describe the flow regime of fresh concrete [10]. Among them, Bingham model is one of the most commonly used models for high-performance concrete [11]. Besides, the lubrication layer is of vital importance in concrete pumping process, which relates to the shear-induced migration of particle inside the pumping pipe [12].

Based on the theory of tribology, the rheological properties of the lubricating layer can be obtained, and the friction on the boundary can be calculated accurately [13]. In addition, the pressure loss has a strong relationship with its discharge rate. The relation curve between linear pressure loss and discharge rate has been obtained by in situ tests [14-18] or the sliding pipe rheometer [19]. The pressure loss can also be obtained by the reverse calculation of the discharge rate, where the discharge rate is integrated by the velocity distribution in the pipe section $[20,21]$. However, the theoretical models cannot be used to predict the actual pressure loss directly because of their implicit expression. Therefore, researches are carried to capture the relationship between the pressure and its governing factors. Due to the yield stress and the plastic viscosity kept relatively constant, the pressure drop shows a linear change with the pipe length increasing [22]. There is a first-order physical correlation between the pressure drop and the flow rate [23]; what is more, a suitable method is given to assess the pressure based on full-size pumping test [24]. This provides a new way to get the pressure, but the full-scale pumping test is time-consuming and labor-costing. Attention is paid on actual concrete pumping project recently. Based on X-ray CT and $3 \mathrm{D}$ mesoscopic numerical simulation, the multiscale mechanic properties change after actual pumping and suggestions for real pumping project are given [25]. A workability box of self-compacting concrete (SCC) suitable for direct pumping up to super tall building is given, among which the yield stress and the plastic viscosity are discussed [26]. Therefore, it is still imperative to develop a simplified pumping pressure loss calculation method of fresh concrete in super high-rise buildings.

To solve the above-mentioned problems, this study aims to establish a simplified pumping pressure estimated method based on mechanical analysis and measurement on spot. The pumping force per meter is attained by computational fluid dynamics. The effects of various factors such as flow rate, lubrication layer thickness, yield stress, and viscosity on the lubricating effect are studied. Afterwards, the calculation results are compared with the high-rise pumping pressure recorded during the Shanghai Tower construction process.

\section{Calculation Method Introduction}

2.1. Force Condition of Pumped Concrete. The actual concrete pumping process is shown in Figure 1. Concrete flows through the pipe line under pressure action supplied by the pump. According to the fluid mechanism, the inlet is taken as velocity type where the value is determined by the actual flow rate. Meanwhile, the outlet is set as pressure type where the velocity is zero. When the concrete flow develops into the stable mode, a representative part of the whole pumping line is separated to undergo a mechanical analysis as shown Figure 1. The fresh concrete is subjected to pressure $(P)$, gravity $(G)$, and friction $(F)$ in the meantime, as expressed in equation (1). The analyzed fresh concrete owns a cylinder shape. Its radius in the ground section and height is expressed by $r$ and $h$, respectively. The friction is equal to the shear stress multiplied by its area as in equation (2), while gravity can be easily obtained by equation (3). where $P$ represents the pumping force $\left(\mathrm{kg} \cdot \mathrm{m} / \mathrm{s}^{2}\right), G$ denotes the gravity-induced force $\left(\mathrm{kg} \cdot \mathrm{m} / \mathrm{s}^{2}\right)$, and $f$ reflects the force caused by friction $\left(\mathrm{kg} \cdot \mathrm{m} / \mathrm{s}^{2}\right)$. $\tau$ and $p$ are the inherent performance of the material, representing the yield stress $(\mathrm{Pa})$ and the density $\left(\mathrm{kg} / \mathrm{m}^{3}\right)$, respectively. $r$ is the radius $(\mathrm{m})$ of the pipe cross section and $h$ is the vertical height of the pumping pipe $(\mathrm{m}) ; g$ is the gravitational acceleration $\left(\mathrm{m} / \mathrm{s}^{2}\right)$.

$$
\begin{aligned}
& P=G+F, \\
& F=\tau A=\tau(2 \pi r h), \\
& G=\rho\left(\pi r^{2} h\right) g,
\end{aligned}
$$

The pumping pressure can be obtained, as shown in the following equation:

$$
P=\Delta P A=\Delta P \pi r^{2}
$$

Based on above equations, the pressure loss is calculated as shown in the following equation:

$$
\Delta P \pi r^{2}=\tau(2 \pi r h)+\rho\left(\pi r^{2} h\right) g .
$$

A simplified form is shown in equation (5) dividing the same parameter at the both sides of equation (5).

$$
\Delta P=\frac{2 \tau}{r} h+\rho g h,
$$

where $\Delta P$ represents the pumping pressure $(\mathrm{Pa})$. According to equation (6), the pumping pressure relates to two factors: the gravity-induced pressure and the frictional-induced one. For the same material, the former one only depends on the pumping height. As for the later one, there are more complicated influential factors. Under the pressure action, the fresh concrete bears a linear shear stress action where it changes zero at the center to peak value at the pipe inner surface. The shear-induced deformation cannot happen unless the shear stress overpasses the yield stress. Therefore, the shear rate shows a linear trend at the deformation area. There is no deformation among the center areas. Consequently, a plug flow is formed (see Figure 2). The discharge rate is obtained by integration on the pipe section.

The fresh concrete takes on Bingham flow in the pipe; its constitutive relationship can be described by equation (7). A correlation can be easily found between the shear rate and the pumping discharge rate. That is to say, the pressure loss along the pipeline can be determined by plastic viscosity, pipe radius, and discharge rate.

$$
\tau=\tau_{0}+\mu \dot{\gamma}
$$




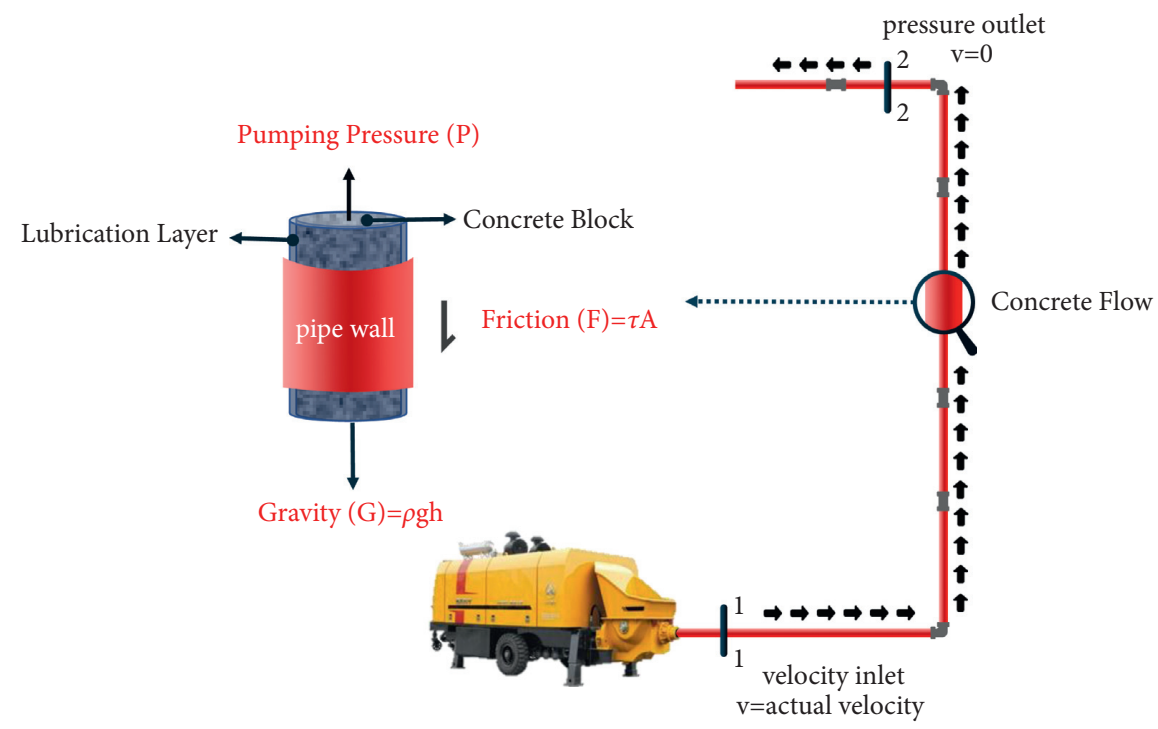

FIGURE 1: The diagrammatic sketch of concrete pumping and its mechanical analysis.

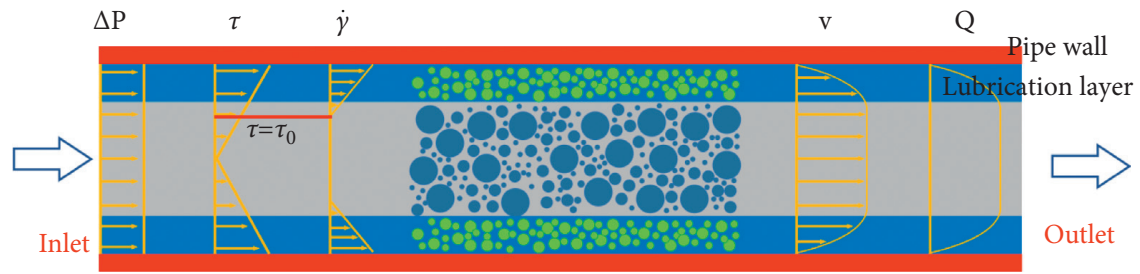

FIGURE 2: Pressure, shear stress, shear rate, velocity, and discharge rate profiles inside a pumping pipeline.

A simplified equation is given when taking equations (1) and (6) into consideration, as shown in

$$
\Delta P=\delta l+\rho g h
$$

where $\delta$ denotes the coefficient of pressure loss along the pipeline $(\mathrm{Pa} / \mathrm{m}), l$ is the total length of the pumping pipe $(\mathrm{m})$, and $h$ represents the height of the pumping pipe (m).

The coefficient $\delta$ in (8) represents the pressure loss per meter, which is determined by rheological parameters, pipe radius, and discharge rate. In this paper, the numerical simulation model is established to determine the coefficient of pressure loss along the pumping pipe.

2.2. Pressure Loss per Meter by Computational Fluid Dynamics. A suitable model is the premise of successful simulation. A 2D symmetrical meshing method is used to simplify the 3D simulation [15]. This method brought a high coincidence degree compared with the in situ test results. In the case that the calculation process is asymmetrical, the $2 \mathrm{D}$ symmetrical method is no longer applicable. Therefore, a 3D simulation model is adopted in this paper. The flow rate is assumed to be constant during the whole pumping process and the length of the calculation unit is set as $10 \mathrm{~m}$. The whole grid establishing process is displayed in Figure 3. As discussed above, a plug flow forms in the $150 \mathrm{~mm}$ pipe. The geometric body is firstly established. For the thickness of the lubrication layer is known as $2 \mathrm{~mm}$ [6], two concentric circles are sketched with a $150 \mathrm{~mm}$ outer diameter and a $146 \mathrm{~mm}$ inner one. Those two circles just empress the concrete block and the lubrication layer. Then, a cylindrical body is formed by image stretching. The 3D model is set up.

The model gird establishment has a remarkable effect on the efficiency and accuracy of simulation analysis. The concrete flow bears friction near the pipe wall where the lubrication layer exists. Thus, the quality of the girds in lubrication layer determines the accuracy of the pressure loss simulation value. Therefore, the whole section is divided into two parts shown in Figure 3. The gird is encrypted to 5 layers in the lubrication layer (blue part shown in Figure 3), with $0.4 \mathrm{~mm}$ thickness of each layer. Meanwhile, the thickness of the mesh in the block area (purple part shown in Figure 3 ) is 5 times that of the lubrication layer. The length of gird is the same on both areas. The mesh size is set as $50 \mathrm{~mm}$ along the pipe direction. It is a consensus that the angel of each two sides should be close to $90^{\circ}$ for the fluid gird. A topological operation called $\mathrm{O}$-grid is imposed on the original gird. The whole section is divided into five parts; the red line empresses its edge. From Figure 3, we can see that the angel of all two sides should be close to $90^{\circ}$ for any gird in any part.

The boundary conditions were defined according to actual pumping. From the mechanical analysis in Figure 1, the inlet is defined as velocity type inlet and the velocity value is determined by the flow rate. The outlet is defined as 


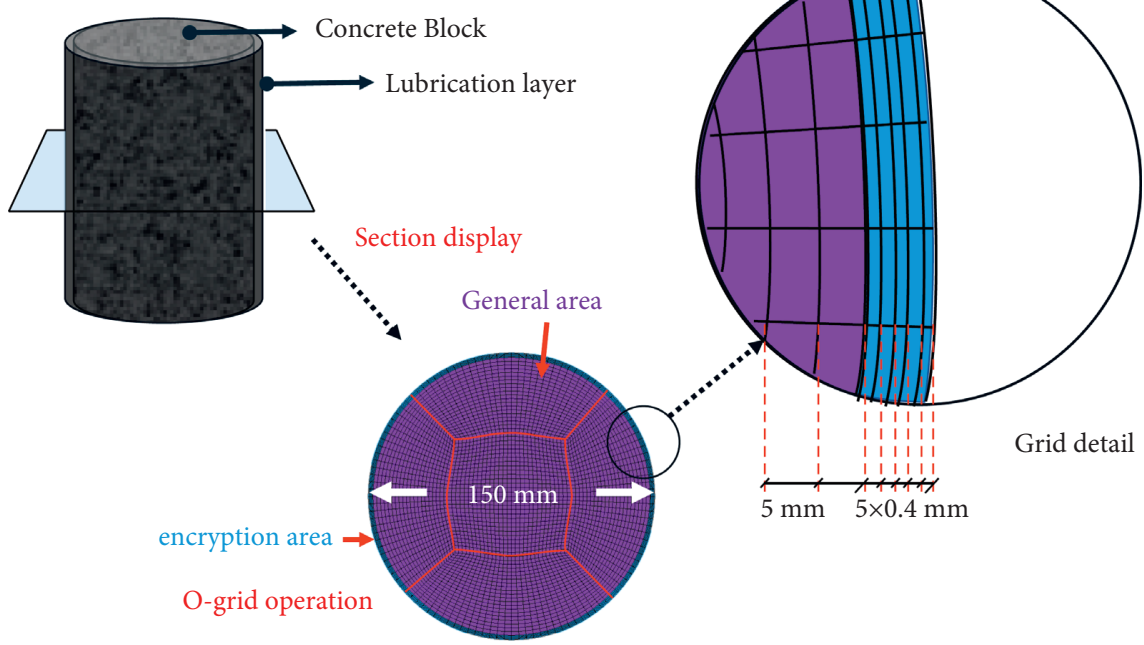

FIgURE 3: The topological mesh considering the lubrication layer.

pressure type outlet where its velocity is zero. There are two velocity inlets and two pressure outlets because of section division. The inner surface of the pumping pipe was set as no-slip wall boundary condition in order to reflect the friction. To ensure that the particles exchange freely on the interface between the lubrication and the block area, an internal contact is set on the contact plane. At last, the calculation step is preset as 1500 with a consideration of both the calculation efficiency and the precision.

2.3. Pumping Conditions. In order to increase the accuracy of simulation analysis, the working conditions design depends on the actual pumping conditions. According to the discussion above, the pressure loss is mainly caused by the gravity and the friction-induced pressure. For the former one, vertical pipe direction with considering gravity action is shown in Table 1, while horizontal one is set as no gravity. For the latter one, it is mainly affected by the concrete velocity, the performances of lubrication layer, which includes the thickness, the plastic viscosity, and the yield stress. The pipe line for actual concrete pumping is composed of the straight pipe and the bend pipe. Thus, there are 6 kinds of influential factors shown as the first row in Table 1. The values are determined by the actual concrete pumping. For example, the bend angles of the bend pipe are $30^{\circ}, 45^{\circ}$, and $90^{\circ}$ in China. Based on the actual concrete pumping discharge, the working conditions for the discharge rate range from 10 to $100 \mathrm{~m}^{3} / \mathrm{h}$. The rest of factors are also designed following the same principle; the whole working conditions are shown in Table 1.

\section{Results and Discussions}

\subsection{Numerical Simulation Results}

3.1.1. The Influence of Lubrication Layer Thickness. Although the thickness of the lubrication layer has obvious influence on the pressure loss of concrete pumping, its exact value is difficult to determine because of the lack of appropriate monitoring measurement. At present, it is a consensus that the thickness of the lubrication is $2 \mathrm{~mm}$. In order to get a generic numerical result, the thickness variable ranges from $1 \mathrm{~mm}$ to $5 \mathrm{~mm}$ during the numerical simulation. The results are shown in Figure 4 . The pressure loss decreases obviously when the thickness of the lubrication increases. Its attenuation is larger when the thickness changes from $1 \mathrm{~mm}$ to $2 \mathrm{~mm}$ or from $2 \mathrm{~mm}$ to $3 \mathrm{~mm}$. When the thickness exceeds $3 \mathrm{~mm}$, the same increment of $1 \mathrm{~mm}$ will lead to smaller pressure loss attenuation. Furthermore, the influence of lubrication layer on pumping performance of concrete is proposed. Its thickness determines the value of pressure loss. In other words, the thickness of the lubrication layer is not enough to provide enough mortar for lubrication, resulting in increased friction in the process of pumping concrete. This trend will be aggravated under high velocity. Therefore, the thickness of the lubrication layer should be chosen accurately according to the actual situation.

3.1.2. The Influence of Gravity. As discussed above, the gravity action plays a significant role in the pressure loss, while it can be calculated by a simple form. To further check its rationality, the pressure loss simulation is carried for different pipe types (horizontal pipe and vertical one) which are commonly used in the super high-rise pumping situations. As for the vertical pipe, the gravity is imposed on the model. According to the rheology test taken before, the yield stress is distributed around $100 \mathrm{~Pa}$ which is also set as input value for simulation, while the plastic viscosity is 60 $\mathrm{Pa} \cdot \mathrm{s}$. Figure 5 presents the pressure loss comparison between the vertical and horizontal pipes under different discharges. It is shown that the pressure difference caused by concrete is close to $0.024 \mathrm{MPa}$, which is almost equal to the hydrostatic pressure value per meter $(0.0245 \mathrm{MPa})$. Therefore, the vertical mode will not be analyzed in the following sections. 
TABLE 1: Working conditions design.

\begin{tabular}{|c|c|c|c|c|c|}
\hline Lubrication layer thickness (mm) & Discharge rate $\left(\mathrm{m}^{3} / \mathrm{h}\right)$ & Plastic viscosity $(\mathrm{Pa} \cdot \mathrm{s})$ & Yield stress $(\mathrm{Pa})$ & Pipe direction & Bend pipe angel $^{\circ}$ \\
\hline 1 & 10 & 10 & 100 & Horizontal & 30 \\
\hline 2 & 20 & 20 & 300 & Vertical & 45 \\
\hline 3 & 30 & 30 & 500 & & 90 \\
\hline 4 & 40 & 40 & 700 & & \\
\hline \multirow[t]{6}{*}{5} & 50 & 50 & 900 & & \\
\hline & 60 & 60 & & & \\
\hline & 70 & 70 & & & \\
\hline & 80 & 80 & & & \\
\hline & 90 & 90 & & & \\
\hline & 100 & 100 & & & \\
\hline
\end{tabular}

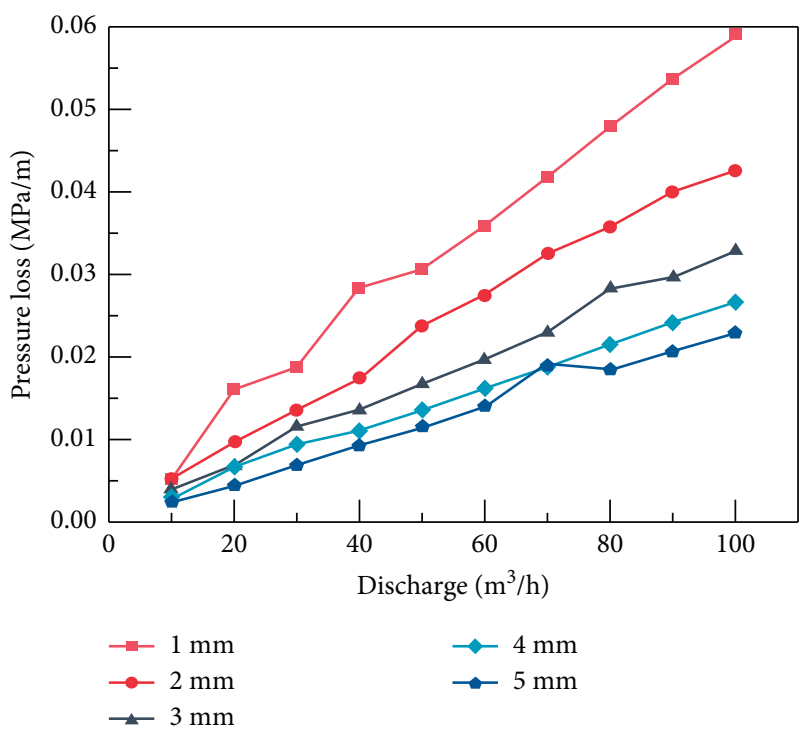

Figure 4: The pressure loss-discharge rate curve under different thickness of lubrication layer.

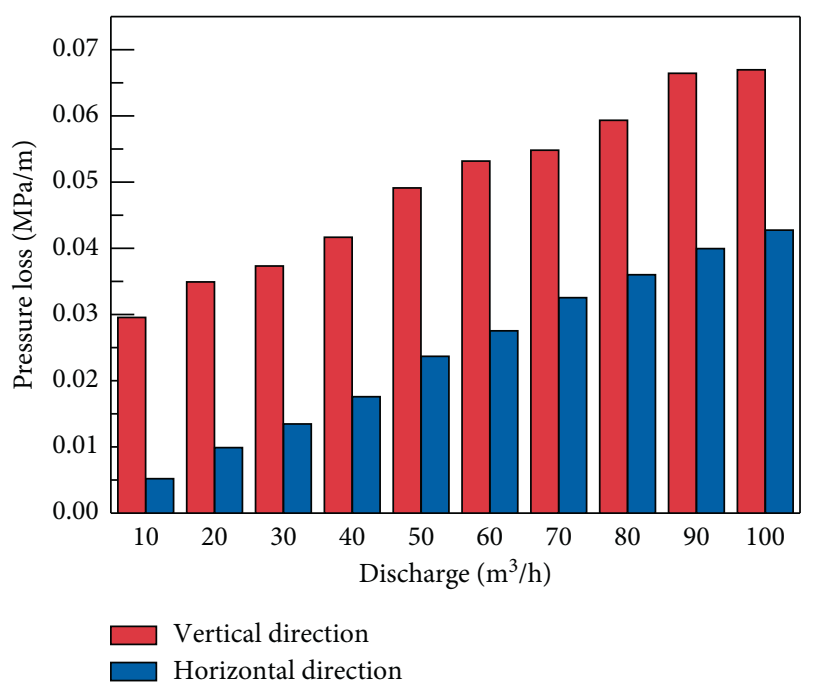

FIgURE 5: The pressure loss comparison between the vertical and horizontal pipes under different discharges.

3.1.3. Sensitivity Analysis. Theoretically, the yield stress is the key factor to determine whether the flow of fresh concrete starts or not, and the plastic viscosity will decrease the flow. However, it is difficult to determine which parameter has more significant effect on the concrete flow in the pipe. Therefore, sensitivity analysis is needed to determine the effect of each parameter. The plastic viscosity values were derived from the experimental flow curve, which were set from 10 to $100 \mathrm{~Pa}$.s. In addition, the yield stress values are selected from 100 to $900 \mathrm{~Pa}$. The thickness of the lubrication is set as $2 \mathrm{~mm}$, while the discharge is fixed at $30 \mathrm{~m}^{3} / \mathrm{h}$ which is commonly used in actual concrete pumping. All this detailed information is shown in Table 1. The relationships between the pressure loss and the rheological parameters (the plastic viscosity and the yield stress) is shown in Figure 6(a). It was shown that the pressure loss increases with the increase of plastic viscosity and yield stress. The slope of the plastic viscosity axis is more abrupt than that of the yield stress axis which can be seen in Figure 6(a). It proves that the plastic viscosity has a more remarkable effect on the pressure loss than the yield stress. Those results for the $125 \mathrm{~mm}$ pipe are shown in Figure 6(b); the tendency is just the same with that of the $150 \mathrm{~mm}$ pipe. It is shown that the pressure loss increases with plastic viscosity and yield stress. The slope of the plastic viscosity axis is steeper than that of the yield stress axis. The results show that the effect of plastic viscosity on pressure loss is more significant than yield stress. According to the flow mechanism of concrete, the yield stress is the flow threshold to determine the flow mode. During the process of flow, viscous hindrance caused by the plastic viscosity should be considered. At present, there are still some obstacles in using rheological parameters to characterize the pumping ability of concrete in practical engineering.

According to fluid mechanics, the velocity (transferred by the discharge rate which is commonly used in actual concrete pumping) is the most remarkable factor affecting the concrete flow. Combined with previous sensitivity analysis, the discharge rate and the plastic viscosity are discussed in this part. There are three kinds of bend pipes for concrete pumping. They are $30^{\circ}, 45^{\circ}$, and $90^{\circ}$. The pressure loss of the $90^{\circ}$ bend pipe (see Figure 7) is discussed with the plastic viscosity and the discharge changing, because it is the type most used in practical engineering. The three axes represent the pressure loss, the plastic viscosity, and the discharge rate, respectively. It can be seen that the pressure loss increases with an increase in either the plastic viscosity or the discharge rate. The slope of the discharge rate axis is more abrupt than that of the plastic viscosity axis. That is to 


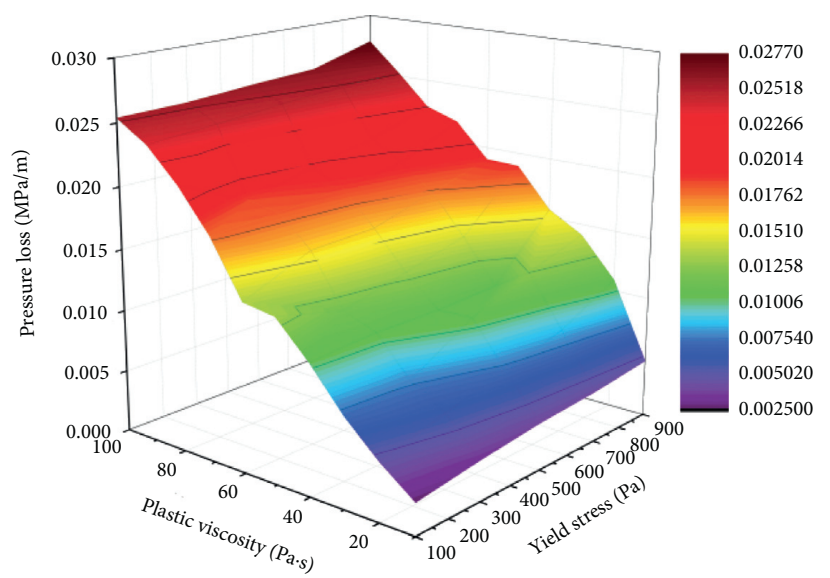

(a)

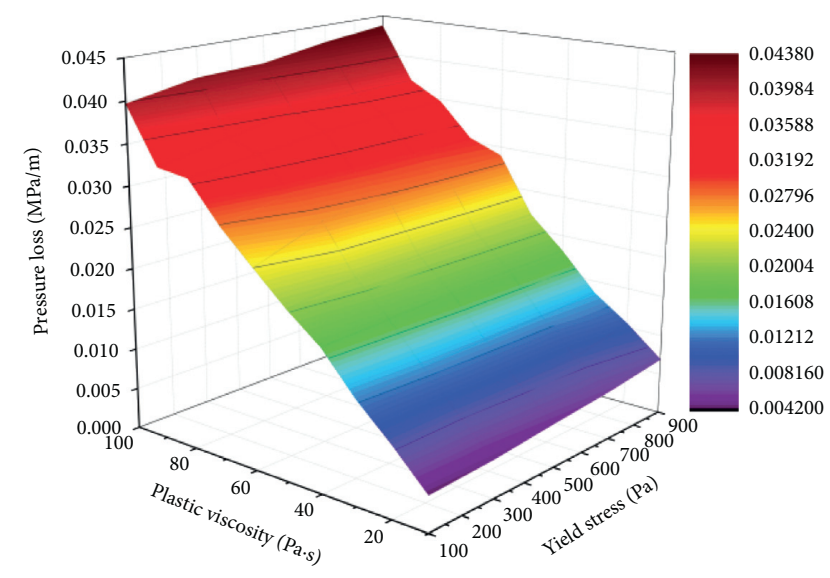

(b)

Figure 6: The change of pressure loss under different rheological parameters: (a) $\phi 150 \mathrm{~mm}$ and (b) $\phi 125 \mathrm{~mm}$.

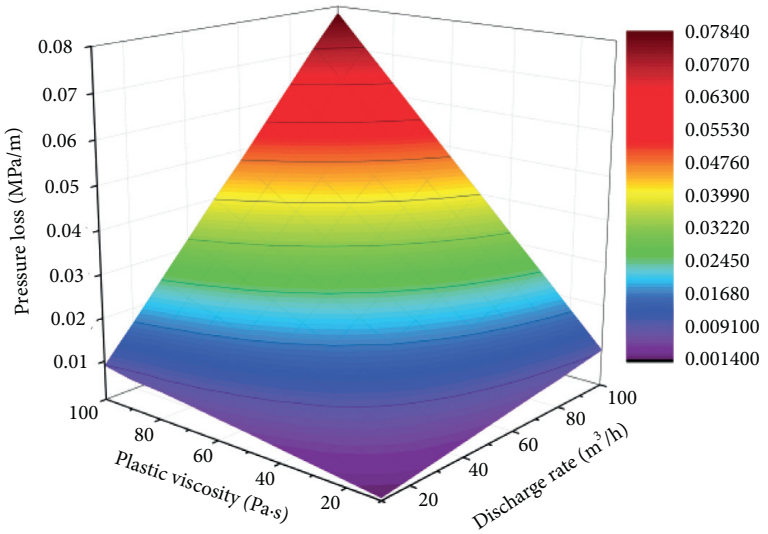

FIGURE 7: The pressure loss change under different discharge and plastic viscosity.

say, the effect of discharge on the pressure loss is more remarkable than that of the plastic viscosity only from a mathematical perspective of view. However, they are different if the physical significance is also taken into consideration. Namely, both the discharge and the plastic viscosity should be taken into account at the same time while the pressure loss is calculated. Besides, the pressure loss of the 90-degree bend pipe is close to that of the straight pipe under the condition that the influential parameters are set equally. It claims that there is no sudden change for bend pipe which is different from the ordinary code.

\subsection{Method Validation}

3.2.1. Project Overview. The Shanghai Tower, $632 \mathrm{~m}$ high, is the tallest building in China at present. It also brings great challenges to the concrete pumping. For one side, the concrete flow ability should be high enough to make sure that the concrete can reach its final height; for another side, the cohesiveness should be enough to avoid segregation during concrete pumping.
According to the concrete performance and structure characteristics, the concrete stress grade changes along the vertical direction. Self-compacting concrete (SCC) is the best choice if the economic factor can be omitted. High workability concrete (HWC) is also used reasonably for economic consideration. The actual construction sense for different heights is shown in Figure 8. The pressure and the discharge are recorded at the same time in order to carry a comparative analysis.

3.2.2. In Situ Pressure Measurements. During the concrete construction in Shanghai Tower, the highest pressure pump (shown in Figure 9) is used in China. The pressure is measured by the record of the dashboard of the fixed pump; then the concrete pumping pressure is obtained according to a specific conversion rule. There are three dashboards on one pump. They are agitating pressure, change-over pressure, and the pressure of the main system, respectively. The main system pressure represents the pressure which conveys the material to the target location, while the rest of pressures mainly reflect the dynamic performances of the pump. The pressure for concrete pumping is a relative pressure value, which is the pressure difference between the inlet and the outlet of the pumping system. The pressure of the outlet is assumed as zero. The actual concrete pumping pressure can be acquired by multiplying the main system pressure with an efficacy coefficient. The concrete pumping discharge and its pumping time are also recorded on the spot. Another key factor, discharge rate, is obtained by a mathematical division operation, for the concrete appears as constant flow in this study. By this method, the original information is obtained during the pumping process.

As this study mainly focuses on the super high-rise concrete pumping, the pumping information is collected for the pumping height over $94 \mathrm{~m}$. The main concrete grades are C70 and C60. The pressure which includes the concrete pressure and the main system pressure is recorded for three different height intervals, while the pumping discharge is also collected at the same time. 


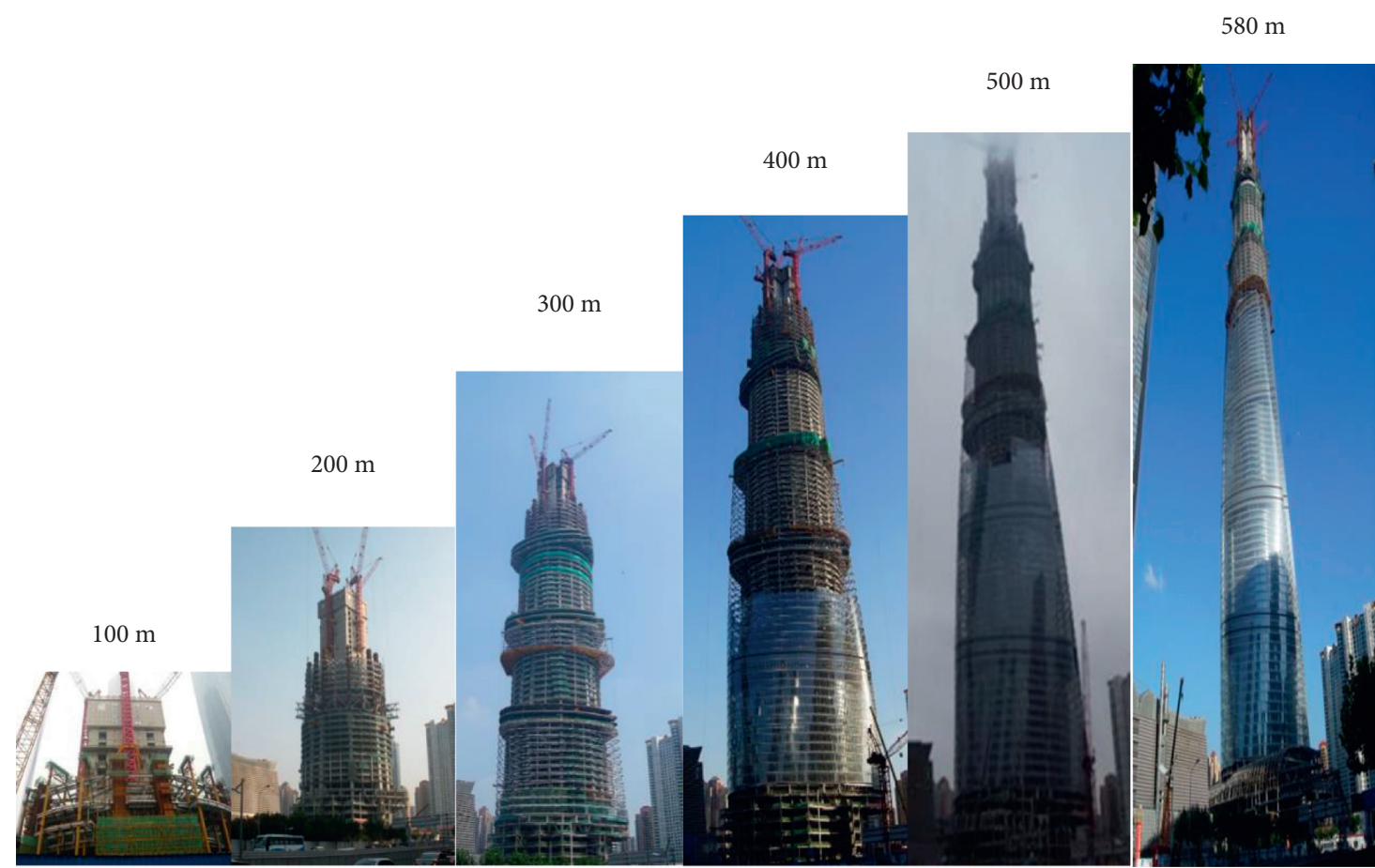

FIGURE 8: The different concrete pumping heights for the Shanghai Tower.

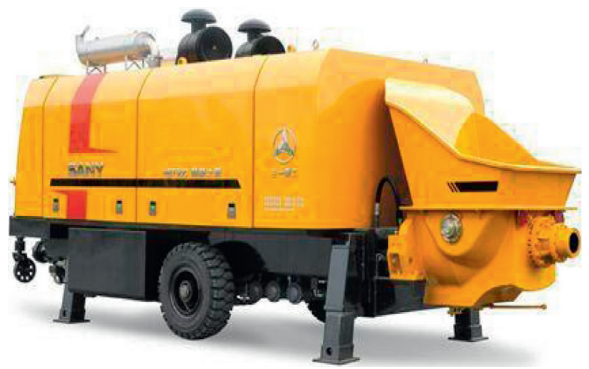

Pump on the spot

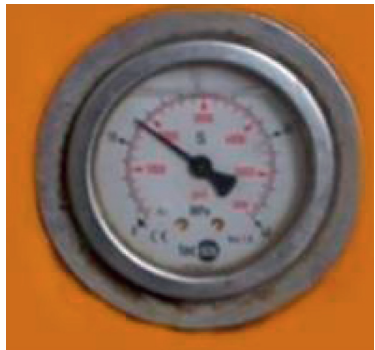

Pressure value

Figure 9: Pressure record via huge pump on the spot.

Pumping height grabs much attention in super high-rise concrete pumping. Thus, the pressure change law along with the pumping height is discussed in this project. Both the main system pressure and the concrete pressure are shown in Figure 10. The whole figure can be divided into three parts according to pumping height and the concrete strength grade. It can be noticed that there is a high positive correlation between the main system pressure and the concrete pressure. When the pumping high interval changes from $94 \sim 164 \mathrm{~m}$ to $240 \sim 310 \mathrm{~m}$, the pressure increases substantially. Curiously, the pressures do not increase obviously with the height growing from the $240 \sim 310 \mathrm{~m}$ interval to $540 \sim 590 \mathrm{~m}$ one. This is mainly because that the discharge decreases below $45 \mathrm{~m}^{3} / \mathrm{h}$ (see Figure 11). On the contrary, they decrease with the height growing such as the $243 \mathrm{~m}$ height and the $250 \mathrm{~m}$ height. A reasonable explanation is that the pressure is affected by multiply factors except for the height. The pressure can also keep decreasing only by slowing down the discharge or reducing the plastic viscosity with the increase of height. In other words, it is necessary to consider all the factors when the pressure law is concluded.

3.2.3. Comparative Analysis. Based on the previous analysis in Section 2, the pressure loss for concrete pumping mainly contains two parts, the pressure caused by the gravity action and the pressure along the pumping pipeline. According to the conveying pipe type, the latter one is further divided into pressure loss for the straight pipe and that caused by the bend pipe. The calculation formula is shown in (9). The key factor for the pressure calculation is $\delta$ (pressure loss). The pressure loss is calculated by its length for the straight pipe, while the pressure loss of the bend pipe is obtained by its number. The pressure loss coefficient is affected by rheological parameters, discharge, pipe diameter, and pipe type. The specific relation between the coefficient and its affected 


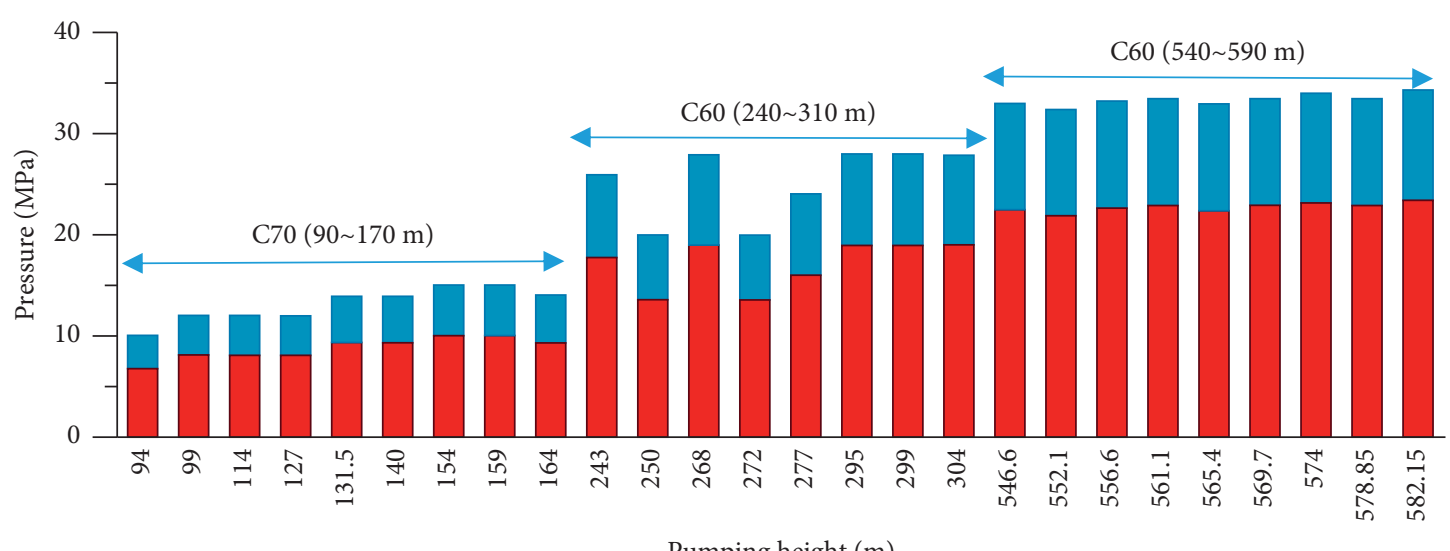

Pumping height $(\mathrm{m})$

Main system pressure
Concrete pressure

Figure 10: The change law between the pressure and the height.

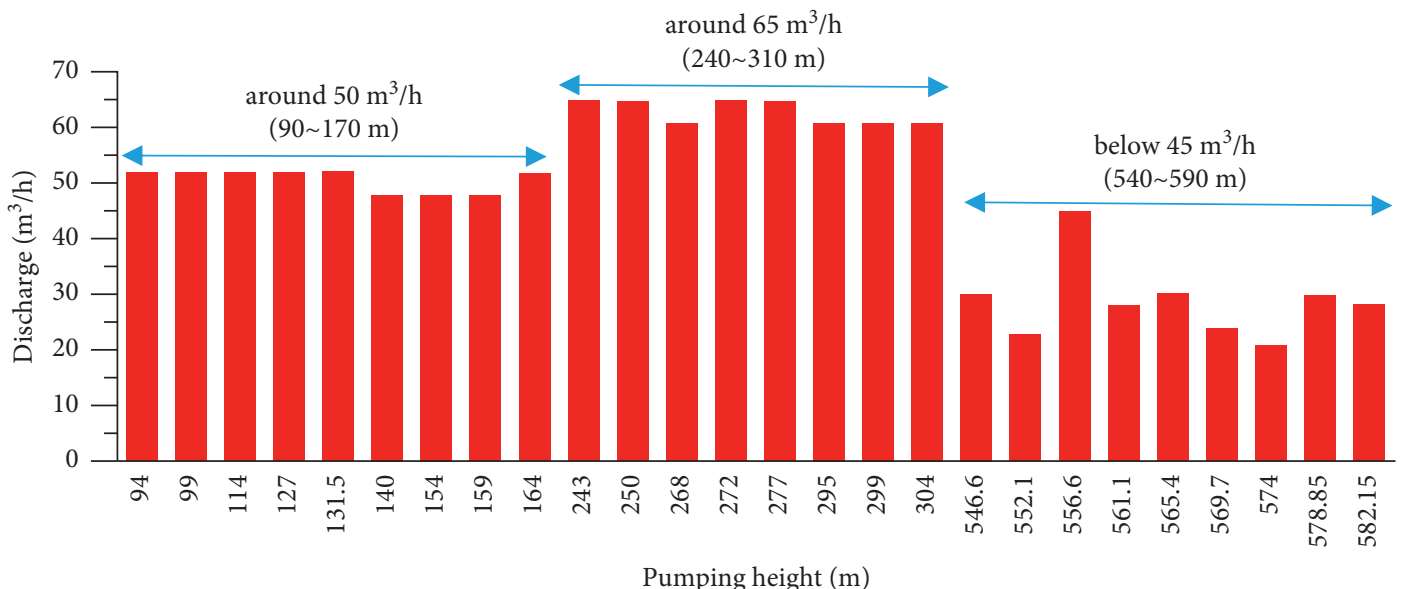

FIGURE 11: The pumping discharge for different pumping height interval.

factors is determined by simulation in Section 3.1. Then, the pressure values can be calculated according to the original information in Shanghai Tower pumping construction. To check the rationality of this method, a compared analysis with the measured data is made in the following part:

$$
\Delta P=\rho g_{h}+\delta_{h} l+\delta_{i} n_{i}
$$

where $\Delta P$ represents the pressure value $(\mathrm{MPa}), h$ denotes the pumping height $(\mathrm{m}), p$ is the inherent performance of the material representing the density $\left(\mathrm{kg} / \mathrm{m}^{3}\right)$, and $l$ reflects the total length of pipe line $(\mathrm{m}) . \delta_{h}$ is the pressure loss coefficient of the straight pipe $(\mathrm{MPa} / \mathrm{m})$, while $\delta_{i}$ represents the pressure loss coefficient of the straight pipe of the bend pipe; $=1,2$, and 3 , represented $90^{\circ}, 45^{\circ}$, and $30^{\circ}$, respectively $(\mathrm{MPa})$. At last, $n_{i}$ reflects the bend numbers.

The coefficient is only related to rheological parameters and discharge rate under the condition that the pipe diameter is fixed. According to the sensitivity analysis of rheological parameters, plastic viscosity plays a dominant role in the pressure loss. A rheological performance test by the rheometer named ICAR is carried with the same concrete mixing proportion of that in this project. The plastic viscosity increases while the slump decreases. It changes from $40 \mathrm{~Pa} \cdot \mathrm{s}$ to $70 \mathrm{~Pa} \cdot \mathrm{s}$, when the initial slump is around $600 \mathrm{~mm}$. It begins at $35 \mathrm{~Pa} \cdot \mathrm{s}$ and ends at $55 \mathrm{~Pa} \cdot \mathrm{s}$, while the initial slump is around $700 \mathrm{~mm}$. Unfortunately, it failed to find a qualitative relationship. Thus, a plastic viscosity average value is adopted for the pressure loss calculation. Appropriate adjustment for the slump is carried based on the actual pumping. At the height interval (243 304 m), the slump decreased to $600 \mathrm{~mm}$, while it enlarges to $700 \mathrm{~mm}$ at the height interval (546 582 m). Finally, the plastic viscosity calculation value is taken as $55 \mathrm{~Pa} \cdot \mathrm{s}$ for the height interval $(243 \sim 304 \mathrm{~m})$, and that is $45 \mathrm{~Pa} \cdot \mathrm{s}$ for the height interval $(546 \sim 582 \mathrm{~m})$. The other parameters are shown in Table 2 according to the project information. Besides, there are four bend pipes with $90^{\circ}$ and two bend pipes with $45^{\circ}$.

To simplify the pressure loss calculation, its controlling chart is drawn by the simulation results. The coefficient can be easily obtained if the plastic viscosity and the discharge are all foreknown. As both the plastic viscosity and the 
TABLE 2: The comparison for the calculated pressure value and measured one.

\begin{tabular}{|c|c|c|c|c|c|}
\hline Pumping height $(\mathrm{m})$ & Plastic viscosity $(\mathrm{Pa} \cdot \mathrm{s})$ & Discharge $\left(\mathrm{m}^{3} / \mathrm{h}\right)$ & Calculated value (MPa) & Measured value $(\mathrm{MPa})$ & Relative error (\%) \\
\hline 243 & 55 & 65 & 16.33 & 17.7 & -7.71 \\
\hline 250 & 55 & 65 & 16.69 & 13.6 & 22.69 \\
\hline 268 & 55 & 61 & 16.86 & 19 & -11.28 \\
\hline 272 & 55 & 65 & 17.79 & 13.6 & 30.80 \\
\hline 277 & 55 & 65 & 18.0 & 16 & -12.75 \\
\hline 299 & 55 & 61 & 18.36 & 19 & -3.39 \\
\hline 295 & 55 & 61 & 18.16 & 19 & -4.41 \\
\hline 299 & 55 & 65 & 19.27 & 16 & 20.48 \\
\hline 304 & 55 & 61 & 17.98 & 19 & -5.39 \\
\hline 546.6 & 45 & 30 & 21.10 & 22.5 & -6.21 \\
\hline 552.1 & 45 & 23 & 19.74 & 22 & -10.27 \\
\hline 556.6 & 45 & 45 & 24.22 & 22.6 & 7.18 \\
\hline 561.1 & 45 & 28 & 21.62 & 22.9 & -5.61 \\
\hline 565.4 & 45 & 30 & 21.77 & 22.5 & -3.26 \\
\hline 569.7 & 45 & 24 & 20.32 & 22.9 & -11.25 \\
\hline 574 & 45 & 21 & 18.86 & 23.1 & -18.35 \\
\hline 578.85 & 45 & 30 & 22.24 & 22.9 & -2.87 \\
\hline 582.15 & 45 & 28 & 22.36 & 23.4 & -4.45 \\
\hline
\end{tabular}

discharge are designed as per ten counts, a linear interpolation is taken to deal with the nondecimal values in the actual concrete pumping. Take the concrete pumping at the $243 \mathrm{~m}$ height level as an example, its plastic viscosity and discharge are $55 \mathrm{~Pa} \cdot \mathrm{s}$ and $65 \mathrm{~m}^{3} / \mathrm{h}$, respectively; then the coefficient can be the average value of those under the condition of (50 Pa.s, $\left.60 \mathrm{~m}^{3} / \mathrm{h}\right),\left(50 \mathrm{~Pa} \cdot \mathrm{s}, 70 \mathrm{~m}^{3} / \mathrm{h}\right),(60 \mathrm{~Pa} \cdot \mathrm{s}$, $\left.60 \mathrm{~m}^{3} / \mathrm{h}\right)$, and $\left(60 \mathrm{~Pa} \cdot \mathrm{s}, \quad 70 \mathrm{~m}^{3} / \mathrm{h}\right)$, respectively. It is $0.026625 \mathrm{MPa} / \mathrm{m}$, while the coefficients of $90^{\circ}$ bend and $45^{\circ}$ angles are $0.028975 \mathrm{MPa}$ and $0.01995 \mathrm{MPa}$, respectively. Then, the pressure loss can be acquired by (9) as follows:

$$
\mathrm{P}=2400 \times 9.8 \times 243+0.026625 \times 393+0.028975 \times 4+0.01995 \times 2=16.33479(\mathrm{MPa}) .
$$

By this way, all the pressures are calculated at different heights. The results are recorded in Table 2. The relative error which reflects the accuracy of the calculated value is obtained by

$$
\text { relative error }=\frac{\text { calculated value }- \text { measured value }}{\text { measured value }} \times 100 \% \text {. }
$$

It can be seen from Table 2 that the relative differences errors between the calculated values and the measured ones can be distributed among 13\%; most of them are within $6 \%$. But there are still exceptions for pressures at such heights including $250 \mathrm{~m}, 272 \mathrm{~m}, 299 \mathrm{~m}$, and $574 \mathrm{~m}$. It can be concluded that this method is reasonable for pumping pressure calculation of the concrete super high-rise pumping. The calculated values of the pressure are generally less than the measured ones because of the plastic viscosity difference between the calculated value and the measured one. The plastic viscosity is supposed to be a constant value for pressure calculation, while it will increase because of the cement hydration and pressure compaction during the actual concrete pumping. Thus, calculation without considering the nonlinear change of the plastic viscosity leads to this negative difference. It still keeps an acceptable scale for the concrete pumping construction under the condition that the concrete can be pumped timely, which means that the fresh concrete is pumping without too long delay after its arrival. Further research is still indeed to consider the effect of the concrete plastic viscosity nonlinear change. Unfortunately, it is impossible to measure the plastic viscosity directly. Its actual change is hard to judge during the pumping process. In a word, it still needs much effort to form a calculated method with high accuracy.

The relative differences between the measured pressure and the calculated value show a huge gap for the pumping heights at $250 \mathrm{~m}, 272 \mathrm{~m}, 299 \mathrm{~m}$, and $574 \mathrm{~m}$ with the biggest one being $30.80 \%$. Either the inaccurate plastic viscosity value or discharge rate value leads to this problem. As we all know, the discharge rate can be recorded directly, while the plastic viscosity is set up by the slump test. Thus, it is definite that the unreasonable plastic viscosity value leads to pressure calculation distortion, which can also be confirmed by the engineer's record on the spot. It is difficult to keep the plastic viscosity uniform for different batches of the concrete with the same mixing proportion. The slump test of the concrete fluctuates with different batches. Therefore, the plastic viscosity can be adjusted according to the actual situation. After consulting the concrete pumping records, it is found that the slumps are close to $700 \mathrm{~mm}$ for those batches of the concrete which are used for pumping heights at $250 \mathrm{~m}, 272 \mathrm{~m}$, and $299 \mathrm{~m}$. The original plastic value is overestimated; then it is adjusted to $40 \mathrm{~Pa}$.s. New calculated pressure is obtained; all 


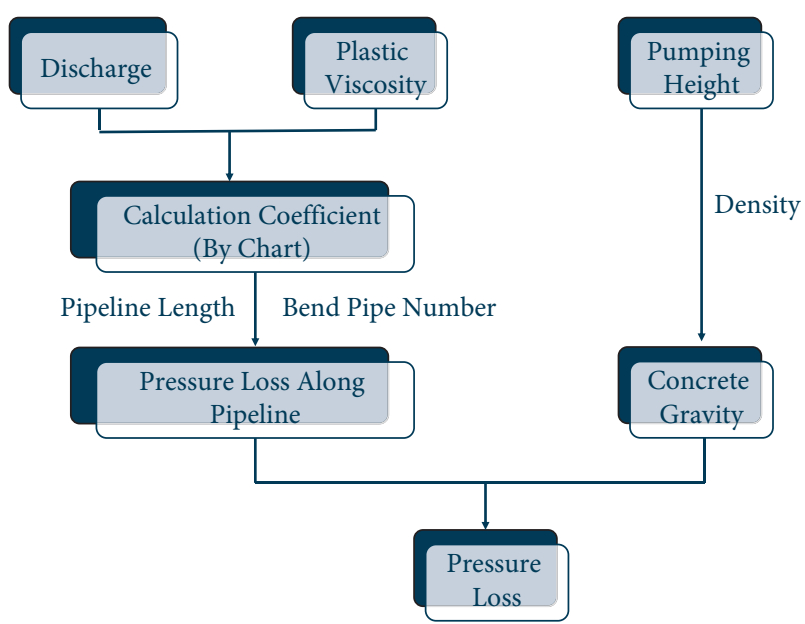

FIGURE 12: The simplified pressure loss calculation method for the concrete pumping.

the relative differences can be controlled within $6 \%$. As for the pressure relative difference at $574 \mathrm{~m}$ height, it is mainly caused by underestimating the plastic viscosity. It is a consensus that a low discharge is adopted for high plastic viscosity concrete. The actual discharge rate is only $21 \mathrm{~m}^{3} / \mathrm{h}$. Thus, the plastic viscosity is enlarged to $55 \mathrm{~Pa} \cdot \mathrm{s}$ according to its slump. The relative difference between the newly calculated value and the measured one is $7.3 \%$, which can suit the construction requirements. In a word, the simplified pressure method, determining the pressure loss coefficient by the pumping discharge and the plastic viscosity, is reasonable, which can estimate the pumping pressure loss for the concrete super high-rise pumping within an acceptable error scale.

3.2.4. Suggestion for Calculation. To further deepen engineers' impression, the simplified pressure calculation method is shown in Figure 12. Considering the deficiencies of the original method, the new method is refunded by the basic mechanic analysis. It can be seen from the figure that the pressure loss caused by gravity can be determined by the concrete density and the pumping height. The pressure loss along the whole pipe can be obtained by the coefficient and the pipe parameters. The coefficient is determined by the plastic viscosity and the pumping discharge together. That is to say, the pressure loss for the concrete super high-rise pumping is easy to estimate by this method if those parameters (see Figure 11) are determined.

Some suggestions are given to enhance its construction application because this method should be combined with the project experience closely. The discharge of fresh concrete has a strong relationship with the project schedule. It is usually a constant value determined by the planned schedule. Compared with the concrete slump, the plastic viscosity is more complicated. For the concrete with the same mixing proportion, the measured plastic viscosity appears as an internal around one fixed value. Before the concrete pumping begins, the concrete preparation work is carried in the laboratory. The plastic viscosity can be obtained at the same time. During the actual concrete pumping, the plastic viscosity will fluctuate because of the uncontrolled factors. Thus, it will lead to the difference between the estimated pressure and the actual value. Therefore, a plastic viscosity interval is given for pressure estimation. Its upper limit is determined by a 10 percent increment for the measured plastic viscosity, while its lower limit is 10 percentage decrements on the measured one. By this means, a reasonably estimated pressure is determined to guide the concrete super high-rise pumping construction.

\section{Conclusions}

As the pressure calculation method is no longer suitable for concrete pumping in present codes, a simplified calculation method which combines the concrete pumping pressure measurement in situ and computational fluid dynamics (CFD) simulation is established in this paper. The following conclusions could be drawn:

(1) The simplified method developed in this paper can be applied to predict the pumping pressure in the super high-rise pumping cases. The relative difference between the calculated pressure loss and the recorded pressure loss in situ can be controlled within $13 \%$. The key factor of this method is pressure loss coefficient, which is determined by interpolation according to the discharge rate and the plastic viscosity.

(2) The pressure loss coefficient is obtained by computational fluid dynamics (CFD) simulation. During the simulation process, the gird in lubrication layer area is encrypted 5 times than that in the block area, and the block part is optimized by the topology method. The results show that this kind of simulation method can be further used in concrete pumping pressure calculation.

(3) A convenient concrete pumping guidance is claimed for engineers in actual projects. Engineers can estimate the concrete pumping pressure according to the plastic viscosity tested in advance and the scheduled pumping discharge before the concrete pumping. If unexpected event happens during the actual concrete pumping, engineers also can adjust the plastic viscosity or the pumping discharge according to this guidance. There still some brief issues needed for further study. Testing technology on spot for concrete pumping should be paid more attention to grab the real thickness of the lubrication. It is urgent to gather more data from other projects like the Shanghai Tower to optimize this simplified method.

\section{Data Availability}

The datasets used and analyzed during the study are included within the manuscript. 


\section{Additional Points}

Highlights. (1) A simplified calculated method is proposed to predict the the pumping pressure. (2) The pressure loss along the pipe is mainly determined by the plastic viscosity and discharge rate of the concrete for a super high-rise pumping. (3) The simulation considering the lubrication layer gains a high accuracy with a topological meshed cross section. (4) The calculated pumping pressure is in good agreement with the test value in super high-rise building situ.

\section{Conflicts of Interest}

The authors declare that they have no conflicts of interest.

\section{Acknowledgments}

The authors would like to thank the engineers from Shanghai Construction Group for their valuable pressure data, in particular Delong $\mathrm{Wu}$ and Jianda Chen. This work was supported by the Open Fund of Innovation Institute for Sustainable Maritime Architecture Research and Technology (iSMART), Qingdao University of Technology (no. 2020-031).

\section{References}

[1] ACI, "Placing concrete by pumping methods," ACI 304.2R-96 Report, ACI Committee, Detroit, MI, USA, 2008.

[2] JCJ, Technical Specification for Construction of concrete Pumping, Architecture \& Building Press, Ministry of Housing and Urban-Rural Construction of the People's Republic of China, Beijing, China, 2011, in Chinese.

[3] L. H. Li, X. W. Chen, M. L. Li, and P. Y. Yan, "Analysis on the changes of pumping pressure of self-compacting concrete in pipes," Construction Technology, vol. 45, no. 12, pp. 52-56, 2016, in Chinese.

[4] P. Y. Yan, M. Y. Li, J. G. Han, and X. Zhao, "Recent development on pumpability of fresh concrete," Journal of the Chinese Ceramic Society, vol. 46, no. 2, pp. 239-246, 2018, in Chinese.

[5] R. J. Phillips, R. C. Armstrong, R. A. Brown, A. L. Graham, and J. R. Abbott, "A constitutive equation for concentrated suspensions that accounts for shear-induced particle migrationv," Physics of Fluids A Fluid Dynamics, vol. 4, no. 1, pp. 30-40, 1998.

[6] J. S. Kim, S. H. Kwon, K. P. Jang, and M. S. Choi, "Concrete pumping prediction considering different measurement of the rheological properties," Construction and Building Materials, vol. 171, pp. 493-503, 2018.

[7] H. Xie, F. Liu, Y. Fan et al., "Workability and proportion design of pumping concrete based on rheological parameters," Construction and Building Materials, vol. 44, pp. 267275, 2013.

[8] V. N. Nerella and V. Mechtcherine, "Virtual sliding pipe rheometer for estimating pumpability of concrete," Construction and Building Materials, vol. 170, pp. 366-377, 2018.

[9] M. S. Choi, Y. J. Kim, K. P. Jang, and S. H. Kwon, "Effect of the coarse aggregate size on pipe flow of pumped concrete," Construction and Building Materials, vol. 66, pp. 723-730, 2014.
[10] M. Nehdi and M. A. Rahman, "Effect of geometry and surface friction of test accessory on oscillatory rheological properties of cement pastes," ACI Materials Journal, vol. 101, no. 5, pp. 416-424, 2004.

[11] W. J. Cui, "Research and application of high performance concrete pumping construction technology in super high-rise structures," Ph D Thesis in Chinese, Tongji University, Shanghai, China, 2018.

[12] S. Jacobsen, L. Haugan, T. A. Hammer, and E. Kalogiannidis, "Flow conditions of fresh mortar and concrete in different pipes," Cement and Concrete Research, vol. 39, no. 11, pp. 997-1006, 2009.

[13] T. T. Ngo, E. H. Kadri, R. Bennacer, and F. Cussigh, "Use of tribometer to estimate interface friction and concrete boundary layer composition during the fluid concrete pumping," Construction and Building Materials, vol. 24, no. 7, pp. 1253-1261, 2010.

[14] D. Kaplan, F. D. Larrard, and T. Sedran, "Avoidance of blockages in concrete pumping process," ACI Materials Journal, vol. 102, no. 3, pp. 183-191, 2005.

[15] M. Choi, N. Roussel, Y. Kim, and J. Kim, "Lubrication layer properties during concrete pumping," Cement and Concrete Research, vol. 45, no. 1, pp. 69-78, 2013.

[16] M. S. Choi, Y. J. Kim, and S. H. Kwon, "Prediction on pipe flow of pumped concrete based on shear-induced particle migration," Cement and Concrete Research, vol. 52, no. 10, pp. 216-224, 2013.

[17] E. Secrieru, D. Cotardo, V. Mechtcherine, L. Lohaus, C. Schröfl, and C. Begemann, "Changes in concrete properties during pumping and formation of lubricating material under pressure," Cement and Concrete Research, vol. 108, pp. 129139, 2018.

[18] D. Feys, K. H. Khayat, A. Perez-Schell, and R. Khatib, "Prediction of pumping pressure by means of new tribometer for highly-workable concrete," Cement and Concrete Composites, vol. 57, pp. 102-115, 2015.

[19] V. Mechtcherine, V. N. Nerella, and K. Kasten, "Testing pumpability of concrete using sliding pipe rheometer," Construction and Building Materials, vol. 53, pp. 312-323, 2014.

[20] S. H. Kwon, S. D. Jo, C. K. Park, J. H. Jeong, and S. H. Lee, "Prediction of concrete pumping: Part I-development of new tribometer for analysis of lubricating layer," ACI Materials Journal, vol. 110, no. 6, pp. 647-656, 2013 a.

[21] S. H. Kwon, S. D. Jo, C. K. Park, J. H. Jeong, and S. H. Lee, "Prediction of concrete pumping: Part II-analytical prediction and experimental verification," ACI Materials Journal, vol. 110 , no. 6, pp. 657-668, 2013 b.

[22] K. P. Jang and M. S. Choi, "How affect the pipe length of pumping circuit on concrete pumping," Construction and Building Materials, vol. 208, pp. 758-766, 2019.

[23] S. Fataei, E. Secrieru, V. Mechtcherine, and N. Roussel, "A first-order physical model for the prediction of shear-induced particle migration and lubricating layer formation during concrete pumping," Cement and Concrete Research, vol. 147, Article ID 106530, 2021.

[24] E. Secrieru, W. Mohamed, S. Fataei, and V. Mechtcherine, "Assessment and prediction of concrete flow and pumping pressure in pipeline," Cement and Concrete Composites, vol. 107, Article ID 103495, 2019.

[25] Y. Li, J. Hao, Z. Wang, Z. Guan, J. Liu, and C. Jin, "Influence of ultra-high-rise pumping on microstructure and multi-scale mechanical properties of concrete based on X-ray CT and 3D 
mesoscopic numerical simulation," Construction and Building Materials, vol. 267, Article ID 120980, 2020.

[26] Y. T. H. Cu, M. V. Tran, C. H. Ho, and P. H. Nguyen, "Relationship between workability and rheological parameters of self-compacting concrete used for vertical pump up to supertall buildings," Journal of Building Engineering, vol. 32, Article ID 101786, 2020. 